\author{
Wiesław FRĄCZ ${ }^{1}$ \\ Grzegorz JANOWSKI ${ }^{2}$
}

\title{
WYKORZYSTANIE PROGRAMU AUTODESK MOLDFLOW® MPI W OPRACOWANIU TECHNOLOGII RTM WYTWARZANIA ELEMENTÓW KOMPOZYTOWYCH
}

\begin{abstract}
W pracy przedstawiono wykorzystanie oprogramowania Autodesk Moldflow MPI do optymalizacji procesu formowania wytworów kompozytowych techniką RTM (ang. Resin Transfer Moulding). Z uwagi na korzyści ze stosowania tego procesu tj.: brak ograniczeń w wielkości i stopniu skomplikowania kształtu detalu, wysoką jakość wyrobów, dobrą kontrolę procesu wytwarzania - metoda ma zastosowanie w przemyśle motoryzacyjnych, okrętowym oraz lotniczym. Obecne na rynku komputerowe programy komercyjne, np. PAM RTM specjalizują się w symulacjach konkretnych metod przetwórstwa tworzyw polimerowych. Tymczasem w wielu firmach wykorzystuje się równocześnie wiele technologii ich przetwórstwa. Mało znana jest w tym kontekście np. możliwość wykorzystania programu Autodesk Moldflow MPI do symulacji wytwarzania wyrobów z kompozytów polimerowych.
\end{abstract}

Słowa kluczowe: przemysł lotniczy, RTM, kompozyty polimerowe, symulacje numeryczne

\section{Wstęp}

Niskociśnieniowe przesycanie żywic w zamkniętych formach - RTM (ang. Resin Transfer Moulding) jest technologią wytwarzania elementów kompozytowych w zamkniętych formach pokrytych żelkotem, gdzie przygotowana wcześniej warstwa zbrojenia ułożona na sucho jest przesycana wtryśniętą żywicą [13]. Końcowe właściwości kompozytu nie zależą wyłącznie od wyboru żywicy oraz włókna - istotną kwestią jest tu również przygotowanie, przebieg, kontrola i optymalizacja procesu. Czynniki te mogą bezpośrednio rzutować na uszkodzenia mikrostruktury materiału, zarówno po stronie żywicy jak i włókien. Proces jest uzależniony od zmiennych parametrów takich jak np.: ciśnienie, temperatura, lepkość, udział objętościowy włókien, czas wtrysku i napełniania [14]. Pręd-

\footnotetext{
${ }^{1}$ Wiesław Frącz - Politechnika Rzeszowska, e-mail: wf@prz.edu.pl

2 Autor do korespondencji/corresponding author: Grzegorz Janowski, Politechnika Rzeszowska, Al. Powstańców Warszawy 8, 35-959 Rzeszów, tel.: (17) 865 1714, e-mail: gjan @ prz.edu.pl
} 
kość wtrysku bezpośrednio determinuje czas wypełnienia formy, nie powinna być zbyt niska $\mathrm{z}$ uwagi na całkowitą impregnację włókien, przedwczesne zastyganie żywicy oraz powstawanie pęcherzy. Bardzo częstym, niepożądanym zjawiskiem jest ruch zbrojenia wewnątrz formy podczas fazy wtrysku wynikający ze zmiany lepkości spoiwa. Ciśnienie wtrysku oraz lepkość żywicy ściśle korelują z temperaturą. Podczas wzrostu temperatury następuje skracanie czasu wypełnienia, a ciśnienia robocze są niższe. Z kolei wzrost lepkości żywicy następuje w przypadku obniżenia temperatury. Typowymi problemami występującymi podczas procesu są: brak całkowitego wypełnienia formy, przesunięcie lub naruszenie struktury wzmocnienia, brak połączenia między żywicą i włóknem, powstawanie pęcherzy powietrznych, skurcz detalu [13].

Ułożenie włókien w kompozytach wytwarzanych metodą RTM przeważnie nie jest skomplikowane. Zachowany musi być odpowiedni stosunek pomiędzy liczbą włókien w kierunku poprzecznym i liczbą włókien w kierunku wzdłużnym. Zbyt duża ilość włókien może powodować niejednorodną strukturę żywicy oraz pogorszenie właściwości mechanicznych wytworzonego detalu. W przypadku uszkodzeń włókien typowym problemem jest przerwanie ich ciągłości, jak również nierównomierne rozmieszczenie w objętości kompozytu, co prowadzi do generowania dużych naprężeń ścinających. W celu ułatwienia procesu RTM często stosuje się preimpregnaty, czyli wstępnie impregnowane żywicami polimerowymi niecałkowicie spolimeryzowanymi włókna w postaci: mat zawierających przypadkowo zorientowane włókna, dwu- lub trójwymiarowych tkanin, oplotów oraz dzianin. Jeśli włókna są nadmiernie sprasowane lub ich zawartość jest zbyt duża, nie ma wystarczającego miejsca na penetrację żywicy, co wydłuża czas napełniania $[7,13,15]$. Żywice polimerowe są stosowane w metodzie RTM ze względu na niską lepkość podczas procesu. W produkcji komponentów lotniczych szczególne wykorzystanie mają żywice: epoksydowe, fenolowe, cyjaninowe i bismaleimidów (BMI) [7].

Kompozyty polimerowe pełnią istotną rolę w wytwarzaniu komponentów lotniczych. Zastosowanie tego typu materiałów wynika z dążenia do ograniczeń zużycia paliwa w trakcie lotu, co jest wynikiem zredukowania masy statku powietrznego przy zachowaniu odpowiedniej tolerancji wymiarów oraz wysokiej jakości powierzchni. Należy pamiętać, że nie tylko ciężar jest istotną cechą materiałów konstrukcyjnych - warto również zwrócić uwagę na takie właściwości jak: odporność na uderzenia, sztywność, właściwości dielektryczne, odporność na zmiany temperatur oraz ciśnień, jak również odporność na korozję [13]. W przemyśle lotniczym technologia RTM po raz pierwszy została wykorzystana do produkcji małych owiewek i kształtek. Bardzo szybko okazało się jednak, że proces RTM ma większe perspektywy zastosowania. Wynikało to z właściwości współczesnych żywic spełniających duże wymagania dotyczące zastosowań konstrukcyjnych. Typowymi przykładami pierwszych części lotniczych, które doprowadziły do rozwoju produkcji metodą RTM są owiewki otworu klapy tylnej ATR Pylon i owiewki Airbusa A321, opracowane przez Aero- 
spatiale i Brochier SA [12]. Ciekawym podejściem zastosowania RTM spełniającym wymagania konstrukcyjne była produkcja łopatki śmigła dla Saab 340 i Fokker 50 opracowane przez Dowty Rotol [11]. Ważnym programem inwestycyjnym, który nadawał tempo procesowi RTM była produkcja podzespołów prototypu F22. Technologię RTM wykorzystano tutaj do produkcji około 325 elementów [16]. W obecnych realiach RTM jest niezwykle rozwiniętą technologią w przemyśle lotniczym, masowo stosowaną do produkcji: pokryw i konstrukcji drzwi wejściowych, powierzchni panelu sterowniczego, osłon silników, łopatek wentylatorów, żeber i elementów skrzydeł, zbiorników paliwa, elementów wału napędowego śmigłowców, elementów śmigła, osłon rakiet w wojskowych statkach powietrznych itp. [4, 6, 13].

\section{Symulacje numeryczne procesu RTM}

Zapotrzebowanie na wysokiej jakości produkty wynikające z presji rynku oraz nowoczesnych wymagań przemysłu lotniczego skłaniają do najszybszego i najbardziej efektywnego projektowania procesów technologicznych. W tym celu podjęto działania zmierzające do ich możliwości symulacji i optymalizacji w oparciu o systemy CAE. Wprowadzenie tych systemów dało korzyści takie jak: skrócenie czasu projektowania, zmniejszenie kosztów zużycia materiałów, optymalizację parametrów projektowych, redukcję czasów konstruowania oraz modyfikacji form. Obecne na rynku komputerowe programy komercyjne, np. PAM RTM specjalizują się $\mathrm{w}$ symulacjach konkretnych metod przetwórstwa tworzyw polimerowych. Tymczasem w wielu firmach wykorzystuje się równocześnie wiele technologii ich przetwórstwa. Mało znana jest w tym kontekście np. możliwość wykorzystania programu Autodesk Moldflow MPI do symulacji wytwarzania produktów z kompozytów polimerowych [1].

Analizy numeryczne wykonane w prezentowanej pracy dotyczyły modelu wręgi kadłuba samolotu. Obejmowały one etapy: przygotowania modelu, jego dyskretyzacji za pomocą elementów skończonych typu tetra, wprowadzenia warunków początkowych i brzegowych, przeprowadzenia obliczeń numerycznych oraz interpretację wyników symulacji. Model wręgi kadłuba samolotu został zaprojektowany $w$ programie NX8. Symulacje numeryczne wykonano w programie Autodesk Moldflow Insight 2013. Na podstawie wstępnie przeprowadzonych analiz ustalono położenie miejsca wtrysku [3]. Rys. 1 przedstawia model numeryczny wypraski, w oparciu o który wykonano analizę procesu RTM wytwarzania wręgi kadłuba samolotu. Jako osnowę polimerową stosowano $w$ symulacjach numerycznych żywicę epoksydową o nazwie handlowej RUTAPOX EA 330 A\&B. Preformę tworzyła mata z włókna węglowego pokrywająca $60 \%$ objętości gniazda.

W celu optymalizacji analizowanego procesu technologicznego zastosowano metodę Taguchi (odporną). Wartości danych wejściowych określano metodą planowania czynnikowego, zwykle stosowaną w planowaniu eksperymentów. 

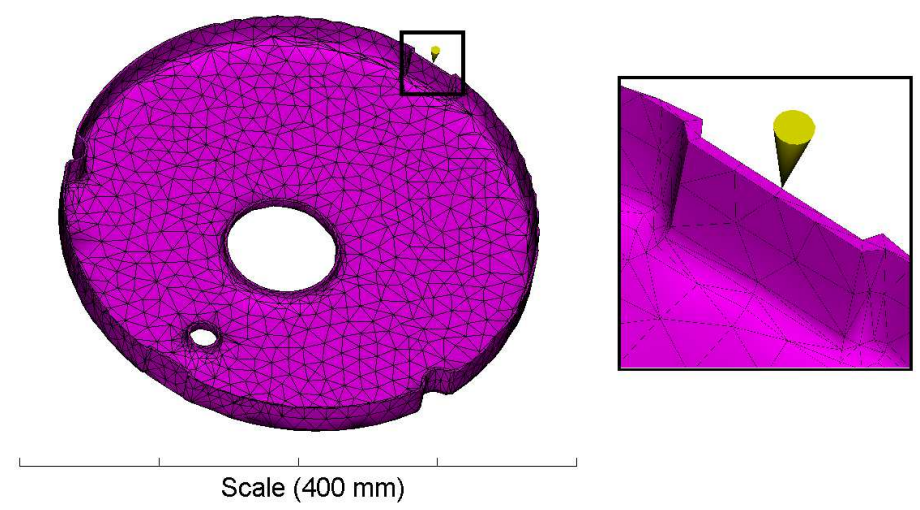

Rys. 1. Model numeryczny detalu (ponad 5tys. elementów ES typu czworościennego) wraz z punktem dozowania żywicy

Fig. 1. The numerical model of the element (over 5 thousand ES type tetrahedral elements) with the point of dosing the resin

W analizach numerycznych stosowano trzy czynniki sterujące, z których każdy podlegał zmianom na czterech poziomach (tab. 1). Podczas doboru zakresu dla czynników sterujących przyjęto wstępnie, iż dla wszystkich spośród przyjętych poziomów zmienności musi być możliwe wykonanie prawidłowego wytworu, ukształtowanego przy minimalnym ciśnieniu oraz przesyconego żywicą w całej objętości gniazda. Zakres parametrów wejściowych ustalono na podstawie literatury [6-10, 13, 14]. Dzięki zastosowaniu planów ortogonalnych Tauguchi, szeroko stosowanych w optymalizacji procesów technologicznych [2, 5] zmniejszono wymaganą liczbę symulacji. W badaniach wykorzystano plan typu $\mathrm{L}_{16}$. Dla potrzeb metody Taguchi zbudowano tablicę ortogonalną (tab. 2), zawierającą 16 kombinacji parametrów podlegających optymalizacji oraz kolumnę zawierającą średnią wartość ciśnienia żywicy na końcu drogi jej płynięcia w gnieździe formy. Po wskazaniu czynników wejściowych i obliczeniu wielkości wyjściowych wybrano kryterium opisujące rodzaj analizowanego problemu. Metoda Taguchi używa w tym celu tzw. wskaźnika S/N (ang. signal-to-noise ratio). Bierze on pod uwagę zarówno wartość średnią sygnału mierzonego, jak i jego odchylenie standardowe. Sposób obliczenia S/N zależy od badanego kryterium jakości. W analizowanym przypadku ciśnienie wypełniania gniazda powinno być możliwie najmniejsze, więc wybrano kryterium: „im mniejszy tym lepszy”. Charakterystykę jakości oraz stosunek wartości sygnału do wartości szumu $(\mathrm{S} / \mathrm{N})$ obliczano z równania:

$$
S / N=-10 \cdot \log \left(\frac{1}{n} \sum_{i-1}^{n} y_{i}^{2}\right)
$$

gdzie: $\mathrm{y}_{\mathrm{i}}$ - średnia wartość ciśnienia w gnieździe formy. 
Na podstawie analizy wpływu głównych czynników na wartość ciśnienia dobrano optymalne parametry procesu: nominalny czas wtrysku żywicy $10 \mathrm{~s}$, temperatura formy $170^{\circ} \mathrm{C}$, temperatura wtryskiwanej żywicy $140^{\circ} \mathrm{C}$. Parametry pokrywają się z parametrami przedstawionymi w tab. 2 (wiersz 3), co nie wymaga przeprowadzenia dodatkowych analiz numerycznych.

Tabela 1. Czynniki sterujące oraz poziomy ich zmienności

Table 1. Controllable factors and their levels of variability

\begin{tabular}{|l|l|l|l|l|}
\hline \multirow{2}{*}{ Czynnik sterujący } & Poziom & Poziom & $\begin{array}{l}\text { Poziom } \\
3\end{array}$ & $\begin{array}{l}\text { Poziom } \\
4\end{array}$ \\
\hline Czas dozowania żywicy $[\mathrm{s}]$ & 1 & 2 & 3 & 20 \\
\hline Temperatura formy $\left[{ }^{\circ} \mathrm{C}\right]$ & 10 & 15 & 25 \\
\hline Temperatura wtryskiwanej żywicy $\left[{ }^{\circ} \mathrm{C}\right]$ & 120 & 150 & 170 & 190 \\
\hline
\end{tabular}

Tabela 2. Zestawienie zmiennych parametrów wejściowych i wyników symulacji - tablica ortogonalna $\mathrm{L}_{16}$

Table 2. List of variable input parameters and simulation results - orthogonal array $\mathrm{L}_{16}$

\begin{tabular}{|c|c|c|c|c|c|}
\hline L.p. & $\begin{array}{c}\text { Nominalny } \\
\text { czas } \\
\text { wtrysku }[\mathrm{s}]\end{array}$ & $\begin{array}{c}\text { Temperatura } \\
\text { formy }\left[{ }^{\circ} \mathrm{C}\right]\end{array}$ & $\begin{array}{c}\text { Temperatura } \\
\dot{z} \text { zwicy }\left[{ }^{\circ} \mathrm{C}\right]\end{array}$ & $\begin{array}{c}\text { Czy forma zo- } \\
\text { stała wypełnio- } \\
\text { na }\end{array}$ & $\begin{array}{c}\text { Ciśnienie we- } \\
\text { wnątrz formy } \\
{[\mathrm{MPa}]}\end{array}$ \\
\hline 1 & 10 & 120 & 100 & TAK & 6,177 \\
\hline 2 & 10 & 150 & 120 & TAK & 0,694 \\
\hline 3 & 10 & 170 & 140 & TAK & 0,1984 \\
\hline 4 & 10 & 190 & 170 & TAK & 9,803 \\
\hline 5 & 15 & 120 & 120 & TAK & 4,336 \\
\hline 6 & 15 & 150 & 100 & TAK & 1,551 \\
\hline 7 & 15 & 170 & 170 & TAK & 9,111 \\
\hline 8 & 15 & 190 & 140 & TAK & 184,2 \\
\hline 9 & 20 & 120 & 140 & TAK & 6,481 \\
\hline 10 & 20 & 150 & 170 & TAK & 5,221 \\
\hline 11 & 20 & 170 & 100 & TAK & 15,99 \\
\hline 12 & 20 & 190 & 120 & TAK & 200 \\
\hline 13 & 25 & 120 & 170 & NIE & - \\
\hline 14 & 25 & 150 & 140 & TAK & 1,375 \\
\hline 15 & 25 & 170 & 120 & TAK & 1,385 \\
\hline 16 & 25 & 190 & 100 & TAK & 200 \\
\hline
\end{tabular}

\section{Analiza wyników symulacji}

W analizie wyników symulacji numerycznych procesu wtryskiwania skupiono się na podstawowych parametrach stanu tworzywa w gnieździe formy tj.: stopniu wypełnienia formy, ciśnieniu wewnątrz formy, występowaniu linii łączenia i pęcherzy powietrznych oraz orientacji włókien maty. Przeprowadzona 
analiza dotyczy optymalnego przypadku parametrów technologicznych. Etapy wypełniania gniazda formy przedstawiono na rysunku 2. Dla danych parametrów konstrukcyjnych i technologicznych stwierdzono, analizując przepływ tworzywa, iż gniazdo formy będzie efektywnie wypełnione.

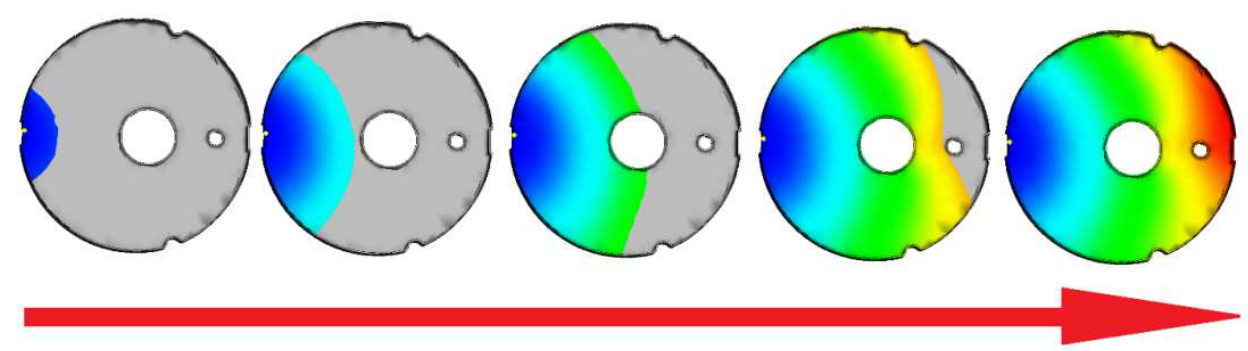

Rys. 2. Etapy wypełniania gniazda formy

Fig. 2. The steps of filling the mold cavity

Z uwagi na to, że technologia RTM jest procesem niskociśnieniowym należy przeanalizować rozkład ciśnień wewnątrz formy (rys. 3). Wielkość ciśnienia jest liniową funkcją odległości od miejsca wtrysku. Im większa odległość od niego, tym mniejsze ciśnienie. Ciśnienie po wtrysku żywicy rozkłada się w gnieździe formy w miarę równomiernie. Na dużej części gniazda utrzymuje się ciśnienie rzędu kilkunastu MPa. Obszary o ciśnieniu równym $0 \mathrm{MPa}$ występują jedynie na końcu drogi płynięcia tworzywa. Na równie niewielkim obszarze gniazda, w pobliżu miejsca wtrysku, występuje maksymalne ciśnienie. Sugeruje to gwarancję dobrych właściwości wyrobu.

Przebieg linii łączenia tworzywa widoczny jest przy otworach oraz na krawędzi wręgi w okolicach miejsca wtrysku (rys. 4). W przypadku technologii wytwarzania powyższego detalu istnieje duże prawdopodobieństwo wystąpienia pułapek powietrznych na krawędziach wręgi oraz w bardzo małym stopniu przy dużym otworze (rys. 5). Najkorzystniejsza orientacja włókien zbrojenia kompozytu została zobrazowana na rysunku 6.

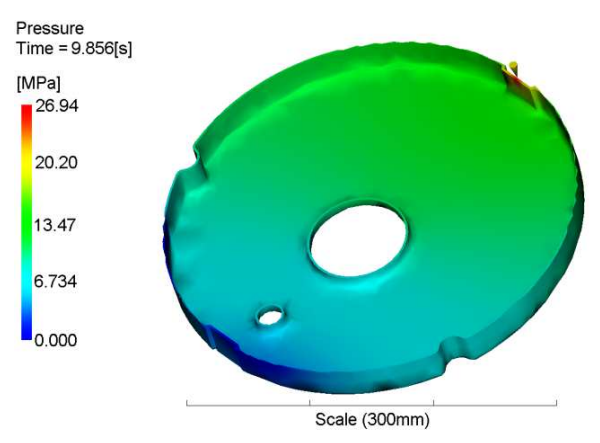

Rys. 3. Rozkład ciśnienia wewnątrz formy

Fig. 3. Pressure distribution inside the form 


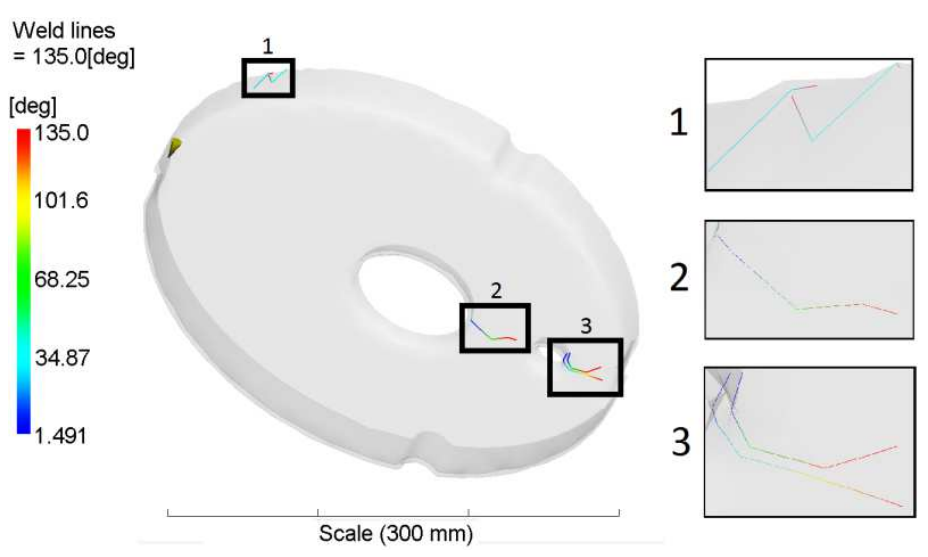

Rys. 4. Wizualizacja możliwości występowania linii łączenia

Fig. 4. Visualization of possibility of the occurrence of weld lines

Rys. 5. Miejsca występowania pułapek powietrznych

Fig. 5. Places of occurrence of air traps

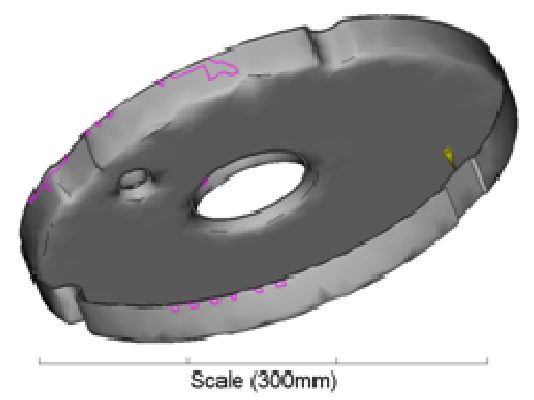

Rys. 6. Najkorzystniejsza orientacja włókien zbrojenia

Fig. 6. The most favorable orientation of the reinforcement fibers

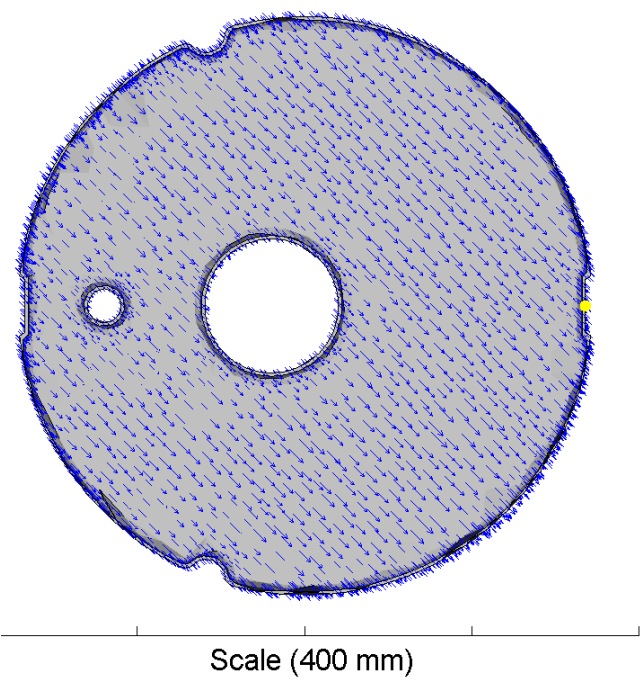




\section{Wnioski}

Wyspecjalizowany program do komputerowej symulacji procesów przetwórstwa tworzyw polimerowych tj. Autodesk Moldflow MPI umożliwia modelowanie i optymalizację technologii formowania wyrobów kompozytowych techniką RTM. Przeprowadzone analizy numeryczne pozwalają dobrać i zoptymalizować parametry technologiczne w procesie wytwarzania kompozytów polimerowych wzmacnianych zbrojeniem włóknistym (maty, tkaniny itp.). Dzięki symulacjom numerycznym można określić takie czynniki technologiczne jak: pewność wypełnienia formy, rozkład ciśnień i temperatury żywicy polimerowej wewnątrz formy, miejsca potencjalnego wystąpienia pęcherzyków powietrza, przebieg linii łączenia strug płynącej żywicy, orientację włókien zbrojenia itp. Wyniki symulacji uwzględnione przy projektowaniu procesu wytwarzania przedstawionego elementu konstrukcyjnego samolotu powinny umożliwić uzyskanie wymaganej jakości detalu oraz pozwolić na zmniejszenie ilości wykonywania prób lub całkowite ich wyeliminowanie.

\section{Literatura}

[1] AMI Resin Transfer Molding, Autodesk® Moldflow® Insight 2012.

[2] Frącz W.: Optymalizacja skurczu wyprasek z wykorzystaniem wyników symulacji 3D, ZN PRz - Mechanika, 83 (4) (2011) 11-22.

[3] Gajdoš I., Duleba B., Spišák E., Greškovič F., Dulebová L.: Optimization of injection molding process by Doe, Hutnik, 81 (2014) 470-475.

[4] Konieczny J.: Materiały stosowane w konstrukcjach lotnictwa wojskowego, Armia, 56 (2013), 68-75.

[5] Korzyński M.: Metodyka eksperymentu, planowanie, realizacja i statystyczne opracowanie wyników eksperymentów technologicznych, WNT, Warszawa 2006.

[6] Kruckenberg T., Paton R.: Resin transfer moulding for aerospace structures, Kluwer Academic Publishers, Dordrecht 1998.

[7] Laurenzi S., Marchetti M.: Advanced composite materials by resin transfer molding for aerospace applications, w Composites and Their Properties, Hu N. (red.), Intech, Rijeka 2012, pp. 197-226.

[8] Lebrun G., Gauvin R., Kendall K.N.: Experimental investigation of resin temperature and pressure during filling and curing in a flat steel RTM mould, Composites, A27 (1996) 347-35.

[9] Lee C.L., Ho J.C., Wei K.H.: Resin Transfer Molding (RTM) process of a high performance epoxy resin. I: kinetic studies of cure reaction, Polymer Eng. Sci., 40 (2000) 929-934.

[10] Lee C.L., Wei K.H.: Resin Transfer Molding Process (RTM) of a High Performance Epoxy Resin. II: Effects of Process Variables on the Physical, Static and Dynamic Mechanical Behavior, Polymer Eng. Sci., 40 (2000) 935-943.

[11] McCarthy RF.J.: Polymer composite applications to aerospace equipment., Composite Manuf., 5 (1994) 83-93. 
[12] Mir L., Leblond E., Auduc H., Bazerque G.: RTM - a process for aircraft structural composite parts. 15th Int. European SAMPE Conf., Society for the Advancement of Materials and Process Engineering, Covina 1994, pp. 171-179.

[13] Potter K.: Resin transfer moulding, Chapman and Hall, Bristol 1997.

[14] Ruiz E., Achim V., Lebel, F.: Characterization, Analysis And Design Of Rtm Process, The 10th Int. Conf. Flow Processes in Composite Materials (FPCM10), Monte Verita, Ascona 2010.

[15] Soutis C.: Carbon fiber reinforced plastics in aircraft construction, Mat. Sci. Eng., 412 (2005) 171-176.

[16] Warwick G.: Building the F-22, Flight Int., 4 (1996) 35-36.

\title{
USE OF THE AUTODESK MOLDFLOW® MPI SOFTWARE IN THE DEVELOPMENT OF RTM TECHNOLOGY OF PRODUCTION OF COMPOSITE ELEMENTS
}

\begin{abstract}
S u m m a r y
In the paper the usage of Autodesk Moldflow MPI to optimize the forming process of composite products using the RTM (Resin Transfer Moulding) technique is presented. Due to the advantages of using this process, i.e. no restrictions in the size and shape complexity of the workpiece, high quality of products, good control of the manufacturing process - the RTM technique is applicable in the automotive, shipbuilding and aircraft industries, and aviation. The available on the market commercial computer programs, e.g. PAM RTM specialize in simulations of specific methods of polymer processing. Meanwhile, many companies use simultaneously many technologies of polymer processing. The possibility to use Autodesk Moldflow ${ }^{\circledR}$ MPI software to simulation of manufacturing polymer composite products is relatively unknown.
\end{abstract}

Keywords: aircraft industry, RTM, polymer composites, numerical simulations

DOI: 10.7862/rm.2015.30

Otrzymano/received: $11.10 .2015 \mathrm{r}$.

Zaakceptowano/accepted: 22.11.2015 r. 